\title{
O Papel da Estatística na Formação do Engenheiro de Produção
}

\section{The Role of Statistics in the Vocational Training of a Production Engineer}

\author{
Geraldo Bull da Silva Junior ${ }^{*}$ \\ Celi Espasandin Lopes ${ }^{* *}$
}

\begin{abstract}
Resumo
Este texto decorre de uma pesquisa de doutorado com o objetivo de investigar como se dá a formação estatística no curso de Engenharia de Produção (EP) em uma Instituição Federal de Ensino da Grande Vitória, Espírito Santo. O referencial teórico centrou-se na Filosofia da Ciência, na Educação Crítica e em teóricos da Educação Estatística. Os dados foram construídos por meio de questionários e entrevistas semiestruturadas. Buscou-se conhecer as necessidades do futuro engenheiro, fragilidades e concepções referentes ao conhecimento estatístico. A partir da Análise de Conteúdo, foram estabelecidas subcategorias que evidenciaram a necessidade de se articular a Estatística a outros componentes curriculares desde o início do Curso. O conhecimento estatístico, elaborado nessa Graduação, apresenta-se fragmentado.
\end{abstract}

Palavras-chave: Ensino Superior. Engenharia de Produção. Ensino de Estatística. Formação inicial. Análise de conteúdo.

\begin{abstract}
This text results from a doctoral research aimed to investigate how the statistical training in the course of Production Engineering (PE) of a Federal Institution of Education in Vitória, Espírito Santo is carried out. The theoretical framework focused on the Philosophy of Science, in Critical Education, and in Statistics Education theorists. Data was built using questionnaires and semi-structured interviews. We attempted to meet the Engineer's needs, weaknesses, and misconceptions about statistical knowledge. From Content Analysis, subcategories were established and they showed the need to articulate Statistics with other curriculum components since the beginning of the course. The statistical knowledge developed at graduation is fragmented.
\end{abstract}

Keywords: Higher education. Production Engineering. Statistics teaching. Initial training. Content Analysis.

\section{Introdução}

Durante sua formação, futuros profissionais de Engenharia de Produção (EP) são submetidos a rotinas de treinamentos e adequação às futuras práticas cotidianas. Também é

\footnotetext{
* Doutor em Ensino de Ciências e Matemática pela Universidade Cruzeiro do Sul (UNICSUL). Docente do Departamento de Engenharias da Faculdades Integradas Espírito-Santenses (FAESA), Vitória, Espírito Santo, Brasil, e da Escola de Aprendizes-Marinheiros do Espírito Santo, em Vila Velha, Espírito Santo, Brasil. Endereço para correspondência: Av. Saturnino de Brito 1350, Praia do Canto, 29055-240, Vitória, Espírito Santo, Brasil. E-mail: gbulljr@bol.com.br.

${ }^{* *}$ Doutora em Educação pela Universidade Estadual de Campinas (UNICAMP). Docente do Programa de PósGraduação em Educação da Universidade São Francisco (USF), Itatiba, São Paulo, Brasil. Docente do Doutorado em Ensino de Ciências e Matemática da Universidade Cruzeiro do Sul (UNICSUL), São Paulo, São Paulo, Brasil. Endereço para correspondência: Av. Gessy Lever, 915/383, Lenheiro, 13272-000, Valinhos, São Paulo, Brasil. E-mail: celilopes@ uol.com.br.
} 
comum retratar o Engenheiro como alguém envolto em pensamentos lógico-abstratos ou debruçado sobre projetos nos quais existem dados para analisar. Isso requer conhecimento estatístico e, portanto, a disciplina deve habilitá-lo a participar ativamente da produção, interpretação e comunicação de dados.

O objetivo principal da pesquisa foi investigar a formação estatística de estudantes de um Curso Superior de EP a partir do problema central a ser respondido: como ocorre a formação estatística de futuros engenheiros de produção? No presente trabalho, consideramos as seguintes questões norteadoras: quais demandas de formação são explicitadas pelos estudantes de EP em relação à Estatística? Quais fragilidades e concepções equivocadas referentes ao conhecimento estatístico são reveladas e percebidas em alunos da EP?

O trabalho de campo foi realizado em uma turma de EP composta por 35 alunos de uma Instituição Federal de Ensino, localizada no município de Cariacica, na Grande Vitória, Espírito Santo. A Estatística, disciplina em foco, é lecionada em dois semestres, sob as denominações de Estatística I (carga horária de 30 horas, oferecida no terceiro período) e Estatística II (carga horária de 45 horas, oferecida no quarto período).

Para a coleta de dados, foram escolhidos dois instrumentos: um questionário e uma entrevista semiestruturada. Apenas 21 dos alunos da turma pesquisada responderam ao questionário em junho de 2013, quando cursavam Estatística I. As oito primeiras perguntas buscavam dados sobre faixa etária, modalidade de Ensino Médio cursada antes da EP (seriado, técnico ou EJA) e se o aluno já havia estudado Estatística nesse nível. Com as demais perguntas, procuramos verificar: o significado prévio do conceito de Estatística de cada aluno; a capacidade de diferenciar Variável Qualitativa, Quantitativa, Discreta e Contínua; se o aprendiz conhecia os gráficos que melhor se adaptam à descrição dessas variáveis; se era conhecido o significado de Variabilidade; se alguém considerava que a Estatística e a Matemática podem contribuir no reconhecimento de aspectos sociopolíticos no exercício de sua profissão; se o aluno tinha alguma sugestão para as aulas da disciplina.

A entrevista foi aplicada a 5 alunos e à professora regente da turma em Estatística I. Todos responderam às mesmas perguntas e, posteriormente, quando cursavam Estatística II, foi colhido outro depoimento e mais uma entrevista foi realizada quando os estudantes cursavam disciplinas que aplicam Estatística. A professora foi entrevistada também mais uma vez, imediatamente após a terceira entrevista dos alunos. Os depoimentos foram registrados em gravação de áudio e transcritos imediatamente, na íntegra, viabilizando a análise do seu conteúdo e a construção dos dados. 
Optamos pela forma de entrevista semiestruturada, por não ser prático deixar o entrevistado divagar ilimitadamente, tornando necessário o estabelecimento de algum limite para as discussões. Foi necessário, então, preparar um roteiro de entrevista, pois não bastaria ir a campo e conversar com os sujeitos da pesquisa. As perguntas foram organizadas em blocos de temas, inspiradas na proposta curricular da Associação Brasileira de Engenharia de Produção - ABEPRO (2001) e na Resolução de n 11, do Conselho Nacional de Educação, da Câmara de Ensino Superior (CNE/CES) de 2002 (BRASIL, 2002).

Nas entrevistas, buscou-se tanto o motivo da opção pela EP como também se o aluno conseguia associar a Estatística às seguintes habilidades requeridas pela ABEPRO (2001): comunicar-se nas formas escrita, oral e gráfica, compreendendo e aplicando a ética e a responsabilidade na profissão (incluindo a avaliação do impacto das atividades da Engenharia no contexto socioambiental); reconhecer se a Estatística capacita o aluno a perceber aspectos humanos, econômicos, sociais e ambientais, dentro de uma visão ética e humanística, atendendo às demandas da sociedade; associar esse conhecimento à modelagem e resolução de problemas; compreender problemas administrativos, socioeconômicos e do meio ambiente; ter responsabilidade social e ambiental; verificar as ligações entre os conteúdos estatísticos e as demandas sociais (posicionando-se politicamente e identificando os itens mais significativos a esse respeito).

A determinação desse grupo entrevistado constituiu-se em um processo intencional que seguiu os seguintes critérios: ter entrosamento com a professora no andamento das aulas; ser aluno que, na primeira prova do semestre, tivesse a nota acima da média da instituição (nota 6,0), mas não necessariamente a mais alta; um aluno reprovado em Estatística I completaria a composição do grupo de entrevistados. Ele foi escolhido por pensar ser importante o depoimento dos extremos (o melhor entrosamento e a reprovação).

Com o primeiro critério, buscou-se alunos com facilidade de compreender e discutir os tópicos da disciplina. O segundo critério serviu para verificar a visão de dois alunos que se encontram em situação confortável em relação à nota para aprovação, mas que, usualmente, não têm destaque por estar em uma zona intermediária de classificação pelas suas notas. Coincidência ou não, os alunos de melhor entrosamento tinham as maiores notas. Verificouse, ainda, ao realizar as entrevistas, uma característica comum a todos: todos tiveram contato com a Estatística no Ensino Médio.

O Aluno 1 foi escolhido para entrevista pela interação com a professora durante as observações de algumas aulas, além de sua facilidade em dialogar sobre os conteúdos. Nascido em 1994, não havia feito outro curso superior. O motivo da escolha da EP foi pelo 
fato de ele querer uma Engenharia na qual pudesse lidar com pessoas, além de considerar essa modalidade mais humana. Ao invés de prender-se a tarefas burocráticas ou ficar à frente de um computador criando instruções, definindo programas, concebendo ferramentas e fazendo simulações, gerir a produção possibilitaria ter mais contato com as pessoas, na sua opinião.

O Aluno 2 foi escolhido pelo mesmo motivo do anterior: destaque na interação com a professora e facilidade para dialogar sobre os conteúdos. Nascido em 1991, estava no terceiro semestre quando a pesquisa foi iniciada e não havia feito outra graduação. Fez curso técnico em Administração durante o Ensino Médio, sendo, inicialmente, motivado a escolher EP por considerar que a modalidade amplia suas possibilidades de atuação. Também pesou o fato de estudar conteúdos de várias áreas das engenharias, o que permitiria ter diante de si mais opções de trabalho e a empregabilidade em alta.

O aluno 3 foi sorteado entre aqueles com nota acima da média na primeira prova, sem que, entretanto, figurasse entre as mais altas. Nascido em 1994, estava no terceiro período sem anteriormente ter passado por outro curso superior e fez curso técnico no Ensino Médio. O que o motivou a escolher EP foi a possibilidade de cursar disciplinas ligadas à Matemática para, posteriormente, pedir isenção em outra universidade, caso fosse aprovado em outro exame vestibular.

O Aluno 4 foi sorteado pelo mesmo motivo do aluno 3: nota acima da média, sem que ela estivesse entre as maiores. Nascido em 1992, também estava no terceiro período no início da pesquisa, sem anteriormente ter passado por um curso superior nem pelo ensino técnico.

O Aluno 5 foi escolhido por ser repetente na disciplina, no semestre em que o trabalho foi iniciado. Nascido em 1984, também estava no terceiro período e havia concluído o Curso Técnico em Gestão Empresarial no Ensino Médio, tendo feito parte da graduação em EP em uma instituição privada.

Completando o grupo de entrevistados, temos a professora de Estatística. Logo após terminar o Ensino Médio (aos 17 anos), ela ingressou no curso de Matemática, concluindo apenas o Bacharelado. Após graduar-se, foi aprovada no Mestrado em Engenharia Ambiental e, concluída essa pós-graduação, retornou à Universidade para formar-se em Estatística. Seu ingresso no quadro de professores da Instituição Federal onde a pesquisa foi realizada ocorreu após terminar a segunda graduação. Atualmente, ela cursa o Doutorado em Engenharia Elétrica, pesquisando a aplicação da Estatística a redes ópticas.

Existem estudos para os quais o método experimental das Ciências Naturais não se adequa, como é o caso das pesquisas de origem sociológica. Na presente pesquisa, após a escolha do viés qualitativo, a opção pela Análise de Conteúdo não foi por acaso, pois essa 
possibilita diferentes modos de se conduzir a construção e a análise de dados. Esse foi o método com o qual puderam ser verificados os materiais resultantes das verbalizações dos entrevistados. Adotou-se o roteiro básico do processo analítico proposto por Bardin (2011), que consiste em pré-análise (quando ocorre o primeiro contato com a documentação), exploração do material e análise dos dados. Na pré-análise, a escolha dos documentos possibilitou interpretar significados, originando novas formulações. Em relação às entrevistas, o contato com o documento e a pré-análise ocorreram após as transcrições, quando as respostas foram organizadas para a tessitura das primeiras considerações, a partir da leitura flutuante. Em se tratando da Análise de Conteúdo, Hsieh e Shannon (2005) sugerem técnicas de abordagens distintas, como é o caso daquela embasada em uma teoria (ou resultados de pesquisas). Como partiu-se de quadros teóricos pré-existentes, essa modalidade foi a mais adequada, possibilitando uma análise mais estruturada, favorecendo a categorização.

Após o contato com as transcrições, objetivando a escolha dos documentos e a composição do corpus (conjunto de documentos a serem analisados), constatou-se que a simples organização individual das entrevistas não seria adequada. Após a primeira abordagem, optou-se por agrupar as respostas pela sequência das perguntas. Com isso, textos foram produzidos nos quais se manifestaram indicadores, explicitados durante a análise. A organização dos dados deu-se a partir da ordenação das respostas em blocos e, na fase seguinte (codificação), os dados brutos foram transformados, expressando o conteúdo. $\mathrm{O}$ procedimento, portanto, seguiu a seguinte orientação: recorte (e a escolha das unidades); enumeração (escolha das regras de contagem); classificação e agregação (escolha das categorias). As unidades de registro foram as respostas, considerada a melhor opção para preparar o material. Assim, a unidade de registro tratou o conjunto das respostas de cada questão, possibilitando a identificação e categorização dos conteúdos.

Definida a forma de registro, as unidades de contexto foram os recortes das declarações dos entrevistados sobre cada tema. Em seguida, verificou-se a ausência e/ou presença de elementos nas falas e a existência (ou não) de termos repetidos nas declarações. Ao categorizá-las, lançou-se mão de processos de classificação e organização, segundo características comuns. As respostas do questionário e da entrevista originaram subcategorias emergentes, utilizadas para classificar os dados, recebendo essa denominação porque foram estabelecidas durante a organização e a interpretação dos dados (FIORENTINI; LORENZATO, 2006). 


\section{A revisão bibliográfica e o referencial teórico}

Para situar em relação ao objeto pesquisado, buscou-se trabalhos sobre Educação Estatística, sendo verificado que, sob essa denominação, abordam-se diversos temas, segundo diferentes referenciais teóricos e distintas metodologias. Realizou-se essa busca no banco de teses e dissertações da Coordenação de Aperfeiçoamento de Pessoal de Nível Superior CAPES, da Biblioteca Digital Brasileira de Teses e Dissertações (BDTD) e do sítio da Universidade Cruzeiro do Sul.

O período pesquisado foi de 2004 a 2013, a partir da palavra-chave Educação Estatística. O corte no ano de 2013 deve-se ao fato de ser o ano imediatamente anterior à qualificação e defesa da tese que originou os dados deste trabalho. Além disso, os bancos de dissertações e teses ainda não disponibilizavam produção de 2014. Foram encontradas 22 dissertações e 10 teses referentes à Educação Estatística no nível superior, sendo que o levantamento não abarca todas as pesquisas sobre o tema. Desejava-se uma aproximação com a produção brasileira e, por tratar-se de pesquisa voltada ao ensino de Estatística no país, a revisão não incluiu trabalhos de outros países.

O ponto comum entre esses trabalhos analisados e esse apresentado é o fato de lidarem com problemas relativos à Educação Estatística, muito embora apenas um deles apresente pesquisa quantitativa, havendo reflexões sobre o ensino de Probabilidade e Estatística, destacando-se sua importância para a compreensão da realidade. Muitas dissertações abordam a necessidade de desenvolver a capacidade crítica, valorizando o conhecimento reflexivo, preparando o aprendiz para interpretar o mundo, e não apenas para a assimilação de técnicas de trabalho proporcionadas pelo conhecimento estatístico.

As discussões incluem a importância das relações interpessoais na aprendizagem de Estatística, pois acredita-se que essas podem favorecer ou prejudicar a compreensão de conceitos e suas aplicações. Na revisão bibliográfica, o conhecimento estatístico emerge como instrumento de discussão de aspectos sociais, históricos e técnicos, servindo de instrumento de percepção de diferentes realidades. Todos os pesquisadores debruçaram-se sobre ocorrências culturais e interpretaram fatos que ocorriam dentro de grupos sociais. Outro fato que também relaciona esses trabalhos ao nosso é a busca pela interpretação de valores, buscando compreender perspectivas de vida e aspectos culturais. O que diferencia a presente pesquisa dos outros trabalhos é que, primeiramente, ela aborda um grupo específico: uma turma de Engenheiros de Produção em formação. Outra especificidade, ainda, é que observa 
demandas de formação explicitadas pelos próprios estudantes, verificando fragilidades e concepções equivocadas em relação ao conhecimento estatístico.

Ao definir tema e abordagem da investigação, percebe-se o teor sociopolítico que as discussões poderiam tomar e que não seria adequado prender a um referencial teórico que tratasse apenas de técnicas estatísticas. O marco teórico inicia, então, com elementos da Educação Crítica e da Educação Matemática Crítica, apontados por Skovsmose (2007) e Alro e Skovsmose (2010). Nesta última obra, é discutida e apontada uma ideologia escolar dominante, fundamentada no racionalismo científico que levou a Educação a caminhos hoje considerados tradicionais. Os autores estudaram situações externas à escola, discutindo ligações do conhecimento matemático com o modelo de democracia em sociedades impregnadas por diversas tecnologias. Eles apresentam e descrevem uma proposta de cenários de investigação, concebidos para aproximar os alunos e proporcionar uma associação de significados, tentando mudar padrões de comunicação tradicionais e favorecer a cooperação.

Skovsmose (2007), por sua vez, discute como o conhecimento matemático em diferentes países instrumentaliza a estratificação social e a ocultação de aspectos sociais, políticos e culturais. Ele também apresenta sua preocupação com o papel da Matemática na graduação, pelo fato de esse nível ser responsável por reconfigurações do saber e formulação de novos conhecimentos. Trata-se, também, de um momento no qual são obtidos novos instrumentos para desenvolver outras ciências e novas tecnologias, acentuando a responsabilidade dos profissionais que atuam nesse nível de ensino.

$\mathrm{O}$ autor reconhece que existem abordagens nas quais os conteúdos escolares são desenvolvidos por meio de exemplos e exercícios, nos quais os dados para a sua resolução são apresentados de forma descontextualizada, objetivando ilustrar imediatamente e instrumentalizar a aplicação de fórmulas, o que chamou de paradigma do exercício. Também cita outro tipo de atividade, denominada semirrealidade, referente a situações artificiais descritas em enunciados que não apresentam qualquer dado ou aspecto externo ao exercício, limitando-se apenas ao que é considerado importante para resolvê-lo e obter uma resposta.

Entende-se que essas duas formas de ensino dificultam a aproximação entre o conhecimento estatístico e outras disciplinas, uma vez que favorecem a assimilação de procedimentos mecanizados de maneira não reflexiva, acostumando o aluno a procedimentos e rotinas de ordens, aceitando a dualidade certo-errado sem que haja argumentação sobre situações reais. Essas práticas condicionam tanto a Educação Superior a moldes tradicionais quanto o aluno a essa dualidade, naturalizando a extensão das rotinas às demais atividades 
cotidianas, servindo apenas à formação, diferenciação e classificação de indivíduos submissos a diversas formas de autoridade, incluindo condições impostas pelo mercado de trabalho.

No contexto das discussões sobre o conhecimento científico como instrumento de controle social, Feyerabend (2007) é uma presença importante, primeiramente por se contrapor ao ensino de Ciências realizado de forma simplificadora, levando à delimitação de campos cada vez mais específicos. Ele opõe-se à ideia de que o conhecimento moderno resulta de um desenvolvimento harmonioso, consolidado por descobertas que descrevam e revelem a ordem racional do universo. Também, aborda a necessidade de relativizar o potencial de explicação atribuído às Ciências, ressaltando que as formas de elaborar e disseminar o conhecimento científico ocultam intenções e relações de poder. Afirma que a prevalência do pensamento científico ocidental, sem a crítica necessária de métodos e conteúdos, proporciona o que ele chama de chauvinismo científico, afastando das Ciências os elementos tradicionais de uma cultura. Para o autor, se o conhecimento científico é absorvido de forma incontestada, cada nova geração tende a reconhecer como justa a superioridade material e intelectual do Ocidente.

Semelhantemente, Demo (2000) considera que o predomínio de uma proposta metodológica leva diferentes campos científicos a se alinharem metodologicamente, com alguns temas e procedimentos passando à preferência de pesquisadores em detrimento de outros. Dessa forma, o autor reconhece que o conhecimento encontra-se em redes de interações, cujos fios da trama são tensionados por diferentes interesses nas comunidades científicas, e cuja produção e disseminação está submetida a métodos de controle, considerando isso um fenômeno político das sociedades contemporâneas que faz do conhecimento científico uma força produtiva e crucial para a reprodução do capital.

Em relação ao ensino de Estatística, Gal e Garfield (1997) apresentam metas comuns aos níveis pré-universitário e de graduação: o aluno deve tornar-se cidadão informado, capaz de compreender e lidar com a incerteza, a variabilidade e a informação estatística no mundo ao seu redor; o ensino deve capacitar o aluno a tomar parte na produção, interpretação e comunicação de dados referentes a problemas em sua vida profissional. Além disso, a Estatística deve ser apresentada como um corpo de conhecimento dotado de modos característicos de pensar, que transcendam à aplicação imediata de métodos específicos de cálculo.

Os autores apontam uma meta global de Educação Estatística: fazer dos alunos cidadãos informados, capazes de compreender e lidar com a incerteza, a variabilidade e a informação estatística, além de tomarem parte na produção, interpretação e comunicação de 
dados. Essa concepção pode ser estendida a diferentes níveis escolares. Também, apresentam metas básicas e inter-relacionadas, a saber: entender o propósito e a lógica das investigações estatísticas; compreender o processo de investigação estatística; dominar habilidades processuais; compreender as relações matemáticas empregadas; compreender a probabilidade e o acaso; desenvolver habilidades de interpretação e de literacia estatística; desenvolver a capacidade de se comunicar estatisticamente; desenvolver dispositivos estatísticos úteis, pois eles também discutem diferentes desafios para a avaliação da aprendizagem da Estatística.

Continuando no campo educacional, temos Curcio, Friel e Bright (2001), que pesquisaram o desenvolvimento da capacidade de ler e compreender informações e dados expressos por gráficos e tabelas estatísticas. Eles consideram que, para compreender informações escritas ou simbólicas, é necessária uma alfabetização específica. Para os autores, é necessário atentar para três aspectos da obtenção da informação: localizar (capacidade de obter a informação dentro de condições específicas), integrar (habilidade de reunir dois ou mais elementos de informação) e gerar informações (habilidade de compreender as informações de um documento e inferir outras, com base no que ele contém).

Como o desenvolvimento da Estatística produziu linguagem, conceitos e símbolos próprios, para aprendê-la, é necessário desenvolver a capacidade de entender suas ideias fundamentais e sua linguagem. O GAISE College Report (FRANKLIN et al., 2005), publicado pela American Statistics Association (ASA - Associação Americana de Estatística) traz um histórico das modificações no ensino de Estatística ao longo do século XX. Elaborado a partir do estudo de normas e orientações para o ensino e a avaliação de aprendizagem dessa disciplina, apresenta uma série de recomendações para o aluno obter bom desempenho em cursos introdutórios de Estatística. Enfatiza que se deve desenvolver o pensamento estatístico e a literacia estatística, entendida como a capacidade de compreender as ideias fundamentais da Estatística e sua linguagem. O pensamento estatístico pode ser definido como aquele utilizado pelos estatísticos para abordar ou resolver os problemas da própria área, o que inclui a necessidade de compreender dados e reconhecer a importância de sua produção. Também faz parte do cenário de formação do pensamento estatístico perceber a presença da variabilidade, conceito essencial ao fazer estatístico, sua quantificação e explicação.

Lopes (2013) lembra que, no século XXI (considerado o da Era da Informação), a análise de dados tornou-se componente essencial do currículo em diferentes níveis. Acrescenta que a realidade, repleta de dados, leva à necessidade de se repensar os currículos, da Educação Básica ao Nível Superior, incluindo a licenciatura em Matemática. Além disso, ressalta que, atualmente, o professor trabalha com alunos que têm acesso cada vez mais cedo 
a diferentes estatísticas. Logo, uma formação centrada na aplicação de fórmulas seguida de exercícios de fixação seria insuficiente para atender as atuais demandas de ensino da disciplina. Cabe, também, superar a concepção de Estatística como Matemática aplicada e percebê-la como uma Ciência de análise de dados, o que requer romper com perspectivas de uma extensão da abordagem matemática, voltada meramente ao de uso de fórmulas, algoritmos e exercícios de fixação. Enquanto o conhecimento matemático não depende de situações externas a si mesmo para se desenvolver, o campo estatístico necessita de diferentes contextos para aplicar seus instrumentos de trabalho.

Como a presente pesquisa foi realizada com indivíduos de uma turma de EP, para discutir aspectos da formação do profissional dessa área do conhecimento, recorreu-se a duas propostas: a das diretrizes curriculares para a graduação, elaborada pela ABEPRO (2001) e aquela contida na Resolução de ${ }^{\circ}$ 11, do CNE/CES (BRASIL, 2002).

\section{A construção e a análise dos dados}

A partir da análise das respostas, surgiram diferentes concepções para a Estatística, por meio das quais pôde-se aprofundar as percepções dos alunos e criar diversas subcategorias. O total de respondentes ao questionário compreende a taxa de retorno de $60 \%$. Dentre os que responderam, dezoito declararam não ter feito antes um curso superior, e dezesseis declararam que estudaram estatística no Ensino Médio. Nenhum deles havia cursado a disciplina anteriormente em qualquer semestre do nível superior e o conceito de variabilidade apresentou-se problemático para o grupo: doze não souberam atribuir significado ao termo. Seis desconheciam possibilidades de articular a Estatística e a Matemática ao reconhecimento de aspectos sociais e políticos. Na resposta à última pergunta, houve sugestão da realização de pesquisa de campo, fazer aplicações práticas, incluir o uso da Informática e a utilização de dados verdadeiros.

O significado atribuído à Estatística obteve respostas variadas, classificadas nas seguintes subcategorias: disciplina curricular, conhecimento aplicável, instrumento de repasse e comunicação de dados e informações e disciplina de caráter matemático. Nas perguntas sobre variáveis qualitativas, quantitativas, discretas e contínuas, houve alunos que não souberam conceituá-las, e outros que desconheciam os conceitos. Apenas um indivíduo conceituou variável qualitativa e nenhum reconheceu a variável quantitativa. Nenhum aluno soube indicar a melhor representação gráfica para variáveis discretas e contínuas. Para a maioria da turma, a Estatística consistia, somente, numa disciplina curricular a mais em sua 
formação profissional (ou mesmo parte da Matemática). Ressalta-se, ainda, que na época da aplicação do questionário os alunos apresentavam deficiências no estabelecimento de redes de significações necessárias à análise e compreensão de situações por meio da Estatística, sendo que, somente alguns consideraram o aspecto utilitário do conhecimento estatístico no cotidiano empresarial (para se analisar o desempenho e tomar decisões).

O documento da ABEPRO (2001) destaca a importância da Estatística para a atuação profissional na $\mathrm{EP}$, mas o conhecimento estatístico não se traduz em instrumento de compreensão de problemas socioeconômicos, políticos e ambientais, se suas aplicações se limitam ao estudo de situações que reportem, exclusivamente, às rotinas da fábrica. Seguindo sugestão de Alro e Skovsmose (2010), pode-se propor que o senso estatístico seja suscitado em diferentes fases do processo de ensino, por meio de investigações que contextualizem as aplicações da referida disciplina.

Como afirmam Gal e Garfield (1997), a Estatística pode contribuir para o aluno tornarse produtor, intérprete e comunicador de dados ao longo de sua vida profissional, e outro desafio para o ensino é estabelecer relações entre posicionamento político e a futura profissão. Conforme Skovsmose (2007), em currículos de áreas predominantemente voltadas para o desenvolvimento de habilidades e procedimentos rotineiros, não se explicitam preocupações com as consequências sociais de uso desse conhecimento.

Além de problemas com classificação e representação de variáveis, parte dos alunos chega à graduação sem saber ler diferentes modelos de gráficos, apresentando deficiências na identificação de significações necessárias à análise e à compreensão de dados representados graficamente (CURCIO; FRIEL; BRIGHT, 2001), existindo fatores capazes de dificultar a compreensão dos gráficos, o que pode estar associado à aprendizagem equivocada de conceitos antes da graduação.

Após realizar as entrevistas, foram categorizadas as percepções passadas pelos entrevistados. Sobre a motivação inicial de cursar EP (primeira pergunta), tem-se três subcategorias: concepções sobre o curso e suas disciplinas, empregabilidade e possibilidades de atuação. Na segunda pergunta, referente às possibilidades de ligações/conexões/relações entre a Estatística e as habilidades requeridas para o exercício da Engenharia, tem-se, por sua vez, seis subcategorias: aplicabilidade, previsão, controle, manipulação de dados, repasse e comunicação de dados e informações e pensamento fragmentados.

Com a terceira pergunta desejava-se saber se o estudante via possibilidades de utilizar a Estatística para identificar influências dos sistemas de produção sobre o ambiente, na qual obteve-se a repetição das subcategorias aplicabilidade, controle e previsão. Na pergunta de 
número quatro, buscava-se saber se o entrevistado relacionava a Estatística às seguintes habilidades: capacidade de identificar, modelar e resolver problemas; ter a compreensão dos problemas administrativos, socioeconômicos e do meio ambiente; ter responsabilidade social e ambiental. As subcategorias repetidas foram aplicabilidade, controle, pensamento fragmentado, previsão e repasse e comunicação de dados e informações, emergindo duas novas: desenvolvimento de habilidades e mensuração.

A pergunta de número cinco arguia sobre a percepção de ligações entre conteúdo de Estatística, demandas sociais e posicionamento político nos elementos citados nas perguntas anteriores, ocorrendo a repetição da aplicabilidade, da manipulação de dados, da mensuração, do pensamento fragmentado e do desenvolvimento de habilidades, emergindo a subcategoria exatidão como novidade. Já com a pergunta de número seis desejava-se saber que temas da Estatística foram considerados mais significativos para a formação em EP, pedindo-se para explicar o(s) motivo(s). Nessa questão, ocorreu a repetição das subcategorias aplicabilidade, mensuração, previsão e desenvolvimento de habilidades e emergiram quatro novas subcategorias: complexidade, modificação de comportamento, relatividade e relevância. A pergunta de número sete fornecia um espaço para que o entrevistado fizesse algum acréscimo ou tecesse comentários/considerações. Nela, ocorreu a repetição das subcategorias aplicabilidade, controle, mensuração, previsão, relevância e modificação de comportamento.

A subcategoria aplicabilidade já havia surgido na categorização das respostas do questionário, revelando que, entre os alunos entrevistados, existe uma vaga percepção da possibilidade para a aplicação da Estatística na análise da evolução do meio político. Isso possivelmente aconteceu porque o tempo destinado à disciplina de Estatística durante o curso era considerado exíguo. Os alunos também não perceberam o fato de que a análise de dados estatísticos fornece elementos para tomadas de decisões práticas, por exemplo, quando da determinação de prioridades em investimentos de infraestrutura. Uma outra percepção que emergiu foi a da Estatística como instrumento de melhoria contínua, que pode ser utilizado para descrever influências dos sistemas produtivos sobre o ambiente, o que é previsto no documento da ABEPRO (2001).

Destaca-se que a noção de ambiente também não foi associada imediatamente a questões ecológicas, mas foi percebida a utilidade do conhecimento estatístico para identificar e compreender elementos que causam impactos ambientais, como no caso de rejeitos gerados por uma fábrica. Porém, a articulação da Estatística com a Ecologia não se mostrou evidente, havendo quem pensasse no conhecimento aplicado aos processos industriais como algo 
imediatamente transferível ao estudo de questões ecológicas. Ao mesmo tempo, o conhecimento estatístico foi identificado com a capacitação do indivíduo para determinar locais apropriados ao destino de resíduos e, nesse aspecto, vemos uma possibilidade de refletir sobre a Estatística como instrumento que permite ao profissional de EP agir conscientemente no ambiente da fábrica, estando preparado para assumir responsabilidades diante da sociedade (SKOVSMOSE, 2007).

A subcategoria repasse e comunicação de dados $e$ informações apareceu, primeiramente, nas respostas do questionário sob a forma de expressões como método para análise mais eficiente dos dados e coleta e análise de dados para obter informações. Quanto à subcategoria controle, surgiu da necessidade de se construir instrumentos para reconhecer as falhas sistêmicas que travam a produção. A percepção da Estatística como instrumento de controle e medição correspondia à ideia de que tudo deva ser mensurado para identificar margens de erro e manter padrões.

O conceito de margem de erro faz do conhecimento estatístico um instrumento de verificação, decisão e aceitação de qualidade do produto e um modo de prever sua lucratividade. Com isso, as aplicações da Estatística ficam na fronteira entre o controle e a previsão, tratando a variabilidade como um inconveniente à produção em série. A Estatística também esteve presente nas entrevistas dos alunos como instrumento de previsão, gerando uma nova subcategoria, na qual a probabilidade foi considerada um instrumento de previsão que capacita a antever possíveis acontecimentos ainda não testados. Isso também foi percebido ao caracterizar a Estatística como instrumento que permite saber como serão a demanda e o comportamento de mercados futuros.

Sobre a subcategoria manipulação, essa foi associada à distorção do entendimento de uma realidade, pois conhecer estatística permitiria confirmar se há manipulação de dados. Isso reforça o pensamento de Gal e Garfield (1997): o aluno deve compreender que processos de pesquisa estatística ajudam a obter conclusões melhores que as baseadas em intuições, devendo aprender a elaborar estatísticas, ao invés de apenas consumi-las. Dessa forma, o Engenheiro de Produção deve ter uma formação diversificada, que possibilite atuar em equipes multidisciplinares, ajudando outras pessoas a compreender e tratar diferentes aspectos das variáveis.

A subcategoria desenvolvimento de habilidades manifestou-se na percepção dos alunos da Estatística como auxiliar do desenvolver do raciocínio lógico, bem como para melhorar a capacidade de resolver os exercícios apresentados, pois também se considerou que isso facilitaria a abordagem de problemas reais. A respeito da subcategoria mudança de 
comportamento, houve alterações de percepção quanto aos usos do conhecimento estatístico. Com a aplicação do questionário, constatou-se que, no início do Curso, a Estatística era considerada apenas mais uma disciplina curricular, ou mesmo uma parte da Matemática. Inicialmente, um dos alunos não via muita utilidade na Estatística e ainda guardava a postura do Ensino Médio, época em que foi submetido a um ensino simplificado, no qual o conhecimento estatístico não possuía vínculos com a realidade. Ao entrar na graduação, ainda lidava com conceitos esparsos e pouco aplicados; porém, no decorrer de sua formação, passou a perceber aplicações mais relevantes da Estatística.

Aqui, deparou-se, novamente, com algo já apontado por Demo (2000), Feyerabend (2007) e Skovsmose (2007), que é o currículo condicionando o aprendiz à lógica de um setor, cumprindo tão somente o papel de selecionar e demarcar competências necessárias à transformação de conhecimento em força produtiva. Os alunos observaram que as aplicações estatísticas ocorreram em momentos relacionados à linha de produção, e as ideias de novas articulações sugeriam a simples transferência de instrumentos e processos de pesquisa da indústria para os estudos socioeconômicos.

A subcategoria relevância emergiu quando os entrevistados, inicialmente, delimitaram as regiões de Probabilidade, fazendo com que a Estatística parecesse exata, quantificando a possibilidades de ocorrer um fenômeno. Os alunos também constataram que as aplicações do conhecimento estatístico são amplas, colaborando tanto para o reconhecimento da necessidade da compreensão dos dados, assim como a importância de sua produção. Eles observaram, ainda, que não basta conhecer os processos de cálculos estatísticos, evidenciando que os resultados devem estar dentro de padrões considerados verdadeiros. Semelhantemente, perceberam a necessidade de verificar a consistência dos dados, o que aponta outra face do desenvolvimento do pensamento estatístico. Além disso, chegaram à conclusão de que, se não houver esse conhecimento, será difícil resolver situações práticas nas Engenharias.

Outros dados merecem destaque: entre os entrevistados, raramente foi percebido que demandas sociais podem ser estudadas quantitativamente, apesar de eles conceberem aplicabilidade quando o tema é o mercado consumidor. Segundo o GAISE College Report (FRANKLIN et al., 2005), é necessário utilizar contextos que relacionem os conceitos estatísticos com o exame de situações reais, o que favorece a criação de redes nas quais os significados são articulados. O uso de dados reais seria uma alternativa para aproximar o estudante do objeto estudado. Associar a resolução de problemas administrativos à Matemática - e não à Estatística - foi outro elemento apresentado nas entrevistas, devido à 
imprecisão atribuída ao conhecimento estatístico, comparando-o aos princípios da certeza e da exatidão, associados ao campo matemático.

Outro aspecto identificado foi o de que medir desempenho não seria restringido apenas à área de Produção, podendo ser aplicado, ostensivamente, a outras situações. Também se observou que o conceito de ética era considerado assunto privado de cada instituição, ocorrendo o mesmo em relação à avaliação de impactos das atividades de engenharias no contexto social e ambiental, também considerado um fator de responsabilidade de cada empresa. Outra ocorrência desse pensamento fragmentado identifica-se pela não articulação de problemas socioeconômicos e ambientais à Estatística. Esse fato colabora para encobrir a realidade de determinadas condições econômicas, deixando-se de perceber o conhecimento como elemento dos jogos de poder que envolvam a utilização da produção científica, com o objetivo de se manterem intactas as relações sociais vigentes (SKOVSMOSE, 2007).

Na prática da EP, o conhecimento estatístico deve ser aplicado como instrumento de resolução para situações complexas, mas notou-se que existe solidão entre as disciplinas, conforme declarou o Aluno1. A partir disso, pode-se concluir que a formação de um Engenheiro de Produção ainda ocorre em meio a saberes desconexos, sendo essa uma manifestação da subcategoria complexidade. Por isso, o ensino deve colaborar para o aluno desenvolver o pensamento estatístico e, nesse sentido, as atividades de campo constituem-se em uma possibilidade didática para confrontar situações reais que levam à mobilização de diversas habilidades. Existe, ainda, a possibilidade de lançar mão de atividades em laboratórios e trabalhos em grupo para promover a discussão de dados, constituindo-se em possíveis instrumentos para o ensino de Estatística sem abrir mão do seu necessário envolvimento complexo com estudos de outros campos. Após estudá-la, e apenas quando vão aplicá-la em diferentes disciplinas da formação profissional, é que os alunos começam a perceber o alcance da disciplina.

Como Feyerabend (2007) destaca, a chamada Educação Científica é excessivamente simplificadora, tornando-se necessário relativizar o potencial do conhecimento científico na compreensão das realidades. Apesar de alguns entrevistados tratarem a disciplina como uma Ciência produtora de respostas exatas houve, também, a percepção de que é impossível se afirmar que os resultados estatísticos se constituem verdade e certeza absoluta. E, como os fenômenos naturais e sociais que se desenrolam no mundo concreto não apresentam apenas resultados exatos, existe a necessidade de se conceber um novo papel social para a Estatística como uma Ciência articuladora de outros saberes em torno de si, ajudando a refletir sobre o conhecimento de uma forma geral. 


\section{Considerações finais}

Em geral, os profissionais da área de Engenharia consideram que o conhecimento estatístico tem grande importância para a sua atuação, enquanto inicialmente trata-se de um obstáculo para os estudantes transporem na sua formação. Os professores da disciplina percebem a angústia dos alunos diante dos conteúdos e a formação estatística em um curso superior de EP, quando apoiada na resolução repetitiva de exercícios e semirrealidades, o que contribui para a elaboração de um conhecimento fragmentado, quando deveria articular a compreensão dos conceitos e a aplicação a situações reais.

Investigou-se, para tanto, a formação estatística inicial nessa área, buscando evidenciar demandas de formação explicitadas pelos estudantes, suas fragilidades e concepções equivocadas. A partir da questão: Como ocorre a formação estatística dos futuros engenheiros de Produção?, estudou-se como o conhecimento estatístico contribui na formação dos alunos, quais são as perspectivas de seu uso no prosseguimento da carreira, que percepções eles têm a respeito da disciplina e suas articulações com outros componentes da matriz curricular do curso, percebendo-se fragilidades e concepções equivocadas envolvendo, por exemplo, as noções de controle, previsão e medição.

No início do trabalho, as evidências coletadas mostravam diferentes percepções sobre a Estatística: parte dos alunos a considerava uma Ciência de análise de dados com aplicações não restritas ao ambiente industrial. Outros, a consideravam apenas um item na formação do Engenheiro. Mas havia uma terceira percepção: a Estatística é disciplina de caráter matemático.

Outro reflexo de um ensino deficitário surgiu em relação à conceituação de Variável (qualitativa/quantitativa, discreta/contínua), ainda quando da aplicação do questionário, indicando desconhecimento da representação gráfica, evidenciando falta de compreensão dos conceitos. Considerando que a análise de dados necessita da compreensão de mensagens expressas graficamente, havia um grupo com deficiências de raciocínio estatístico e de literacia. Em relação aos problemas de interpretação de gráficos, ao invés de propor situações nas quais a sua leitura se destine apenas ao reconhecimento de números sobre os eixos, podese propor atividades nas quais esse instrumento de comunicação de dados suscite discussões onde os valores apresentados tenham seu sentido discutido.

No decorrer das entrevistas, observou-se mudanças de percepção em relação ao alcance da Estatística, mas, ao mesmo tempo em que horizontes se ampliavam, algumas visões permaneceram inalteradas, devido a ideias trazidas do Ensino Médio. Média, moda, 
variância e desvio-padrão começaram a ser melhor compreendidos, a partir do momento em que passaram a ser utilizados como instrumentos de resolução de problemas e descrição de processos de outras disciplinas. Em Estatística II, a probabilidade passou a fazer parte da análise de dados e foi quando a disciplina se tornou relevante. Habilidades foram desenvolvidas e inseridas em situações complexas, tendo o reconhecimento de sua utilidade como mais um instrumento de comunicação.

O aluno de EP, geralmente, não entende que se faz necessário adaptar os instrumentos estatísticos aplicados ao planejamento e supervisão da produção para o estudo de situações de caráter social, principalmente as relacionadas a problemas socioeconômicos e ambientais. Nesse ínterim, manipulação, previsão e controle foram concepções encontradas nos depoimentos, que incluíram a possibilidade de manipular resultados, possibilitando perceber a realidade segundo diferentes conveniências e interesses, desvirtuando o resultado de um levantamento estatístico.

Outra importante aplicação percebida para a Estatística diz respeito ao planejamento e/ou à previsão de ações ou levantamentos de quadros futuros. Seja na esfera pública ou privada, possibilitaria descrever e detalhar influências da atividade industrial sobre a sociedade em geral. Além disso, constatou-se que a Estatística favorece a elaboração de planos para controle de falhas na produção, muito embora não se devesse considerar o conhecimento estatístico simples instrumento para verificação de margens de erro ou indicar a lucratividade de um empreendimento. Uma possibilidade diante da necessidade de o aluno ser produtor, intérprete e comunicador de dados é, ainda em Estatística I, utilizar, por exemplo, dados populacionais reais e outros ligados à descrição de impactos ambientais causados por diferentes modalidades de exploração extrativista e instalações industriais.

Ressalta-se que o ensino de Estatística não deve ficar restrito ao desenvolvimento econômico ou tecnológico, pois continuaria atrelando a formação profissional ao panorama de descuido com a vida e o ambiente. É necessário, portanto, formar Engenheiros de Produção cada vez mais competentes para o desempenho de suas funções, sem dissociar a formação profissional do exercício da cidadania. As Ciências e seus desdobramentos tecnológicos não podem ficar à mercê de aspectos utilitários, tais como o binômio lucro/prejuízo, devendo ser aplicado o conhecimento estatístico para que possa contribuir com a preservação da vida no planeta.

No caso da aplicabilidade, do repasse e comunicação de dados e informações, do controle e da medição, pode-se pedir que os próprios alunos busquem dados referentes às necessidades de infraestrutura da própria cidade, tais como a necessidade de ampliação da 
rede de distribuição de água e de tratamento de esgoto. Pode-se, além disso, discutir temas como a mobilidade urbana e a necessidade de criação de linhas e/ou novos horários baseados em dados apurados pelos próprios estudantes de EP. Isso possibilitaria aplicar os instrumentos estatísticos aprendidos, mostrando, inclusive, as limitações em relação aos instrumentos de medição proporcionados pela Estatística e a necessidade de avaliações de caráter qualitativo a partir dos números obtidos, incluindo, aí, a compreensão do que é uma margem de erro relativa a uma previsão de horários de ônibus.

Percebe-se, portanto, que geralmente não há orientação acerca da possibilidade de articular o saber estatístico e o dia a dia em sociedade com as atividades específicas de um Engenheiro de Produção. O estudo de mobilidade urbana, privilegiando um trabalho com dados relativos à própria região onde se encontra a instituição de ensino, pode ser um tema de fundo para mobilizar outras disciplinas como, por exemplo, aquelas que tratam do desenvolvimento de linguagens de programação.

Existem demandas a explorar, tais como a necessidade de compreender os conceitos estatísticos, dominar sua literacia e desenvolver o pensamento estatístico, ao invés de valorizar a mera manipulação de fórmulas. Acredita-se, nesse sentido, que o estudante de EP pode ser orientado a perceber que as aplicações da Estatística não envolvem apenas as ações de medir, prever e controlar. Até os materiais didáticos têm de ser adequados, adotando novos usos para as tecnologias existentes, renovando-se o currículo e adotando outras formas de abordagem dos conteúdos. Atividades investigativas e o uso de dados reais serviriam para aproximar o aluno de diferentes realidades, o que também contribuiria para se lidar com diversas situações, cujos padrões de resolução não teriam sido previamente estabelecidos.

Entende-se, ainda, que, em todos os níveis de escolaridade, é importante associar o conteúdo técnico à realidade do educando, necessitando a reflexão sobre o que corre nos cursos de Engenharia de Produção devido à falta de ligações entre o que se aprende e a realidade fora do ambiente industrial. Como consequência dessa dissociação, percebe-se profissionais que, tão somente, sabem lidar com equipamentos e instalações, enquanto o ideal seria a Educação não cumprir apenas a tarefa de tornar o indivíduo hábil para manipular conceitos. É necessário, assim, desafiá-lo sempre a romper o estágio de conhecimento em que se encontra, pois o estudante necessita ser, constantemente, estimulado a observar as consequências de sua atuação. Isso representa um grande passo para que o Engenheiro de Produção, além de ser um técnico qualificado, torne-se um cidadão atuante na sociedade. 


\section{Referências}

ALRO, H.; SKOVSMOSE, O. Diálogo e aprendizagem em educação matemática. 2. ed. Belo Horizonte: Autêntica, 2010.

ASSOCIAÇÃO BRASILEIRA DE ENGENHARIA DE PRODUÇÃO. Referências curriculares. 2001. Disponível em: 〈http://www.abepro.org.br/arquivos/websites/1/DiretrCurr19981.pdf>. Acesso em: 18 jul. 2013.

BARDIN, L. Análise de conteúdo. São Paulo: Edições 70, 2011.

BRASIL. Ministério da Educação. Conselho Nacional de Educação. Câmara de Educação Superior. Diretrizes curriculares nacionais do curso de graduação em engenharia. Brasília: CNE/CES, 2002. Disponível em: 〈http://portal.mec.gov.br/cne/arquivos/pdf/CES112002.pdf〉. Acesso em: 21 out. 2014.

CURCIO, F. R.; FRIEL, S. V.; BRIGHT, G. W. Making sense of graphs: critical factors influencing comprehension and instructional implications. Journal for Research in Mathematics Education, Reston, v. 2, n. 2, p. 124-158, 2001. Disponível em: <http://www.jstor.org/discover/10.2307/74 9671 ?sid=21105750687673\&uid=2\&uid=4>. Acesso em: 23 jul. 2013.

DEMO, P. Metodologia do conhecimento científico. São Paulo: Atlas, 2000.

FEYERABEND, P. K. Contra o método. São Paulo: Unesp, 2007.

FIORENTINI, D.; LORENZATO, S. Investigação em educação matemática: percursos teóricos e metodológicos. Campinas: Autores Associados, 2006.

FRANKLIN, C. et al. GAISE college report: guidelines for assessment and instruction in statistics education: college report. American Statistical Association, San Francisco, 141p., fev. 2005. Disponível em: <http://www.amstat.org/education/gaise/GaiseCollege_Full.pdf $>$. Acesso em: 23 set. 2013.

GAL, I.; GARFIELD, J. Curricular goals and assessment challenges in statistics education. In: The assessment challenge in statistics education. Haia: IOS Press, 1997. p.1-13. Disponível em: <https://www.stat.auckland.ac.nz/ iase/publications/assessbkref $>$. Acesso em: 23 jul.2013.

HSIEH, H. F.; SHANNON, S. E. Three approaches to qualitative content analysis. Qualitative Health Research, Thousand Oaks, p.1277-1288, nov. 2005. Disponível em: <http://qhr.sagepub.com/content/15/9/1277>. Acesso em: 25 jun. 2014.

LOPES, C. E. Educação estatística no curso de matemática. Bolema - Boletim de Educação Matemática, Rio Claro, v. 27, n. 47, p. 901-905, dez. 2013. Disponível em: <http://www.scielo.br/pdf/bolema/v27n47/10.pdf >. Acesso em: 20 ago. 2014.

SKOVSMOSE, O. Educação crítica: incerteza, matemática, responsabilidade. São Paulo: Cortez, 2007.

Submetido em Junho de 2015. Aprovado em Novembro de 2015. 